\section{Novel Endosonographic Findings in Cronkhite-Canada Syndrome}

\section{E. M. Ward, H. C. Wolfsen, M. Raimondo} Division of Gastroenterology and Hepatology, Mayo Clinic, Jacksonville, Florida, USA

Corresponding Author

\section{H. C. Wolfsen, M.D.}

Division of Gastroenterology and Hepatology

Mayo Clinic

4500 San Pablo Road

Jacksonville, FL 32224

USA

Fax: $\quad$ + 1-904-953-7260

E-mail: pdt@mayo.edu

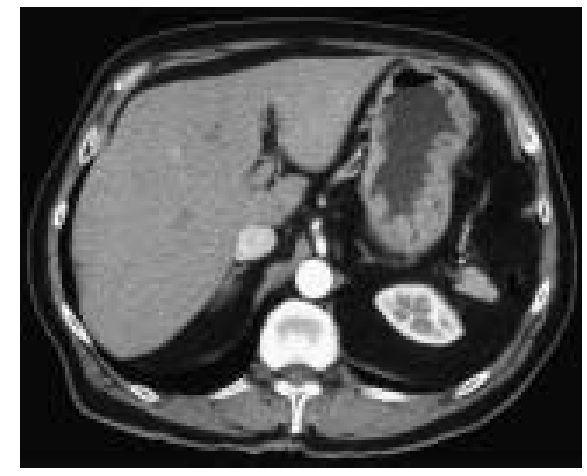

Figure 1 The CT scan shows markedly thickened gastric walls in a patient with CronkhiteCanada syndrome.

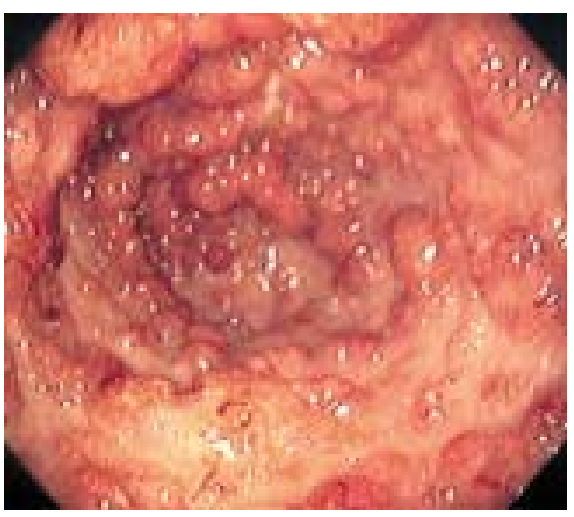

Figure 3 Endoscopic appearance of the distal stomach, showing innumerable microcystic polyps.

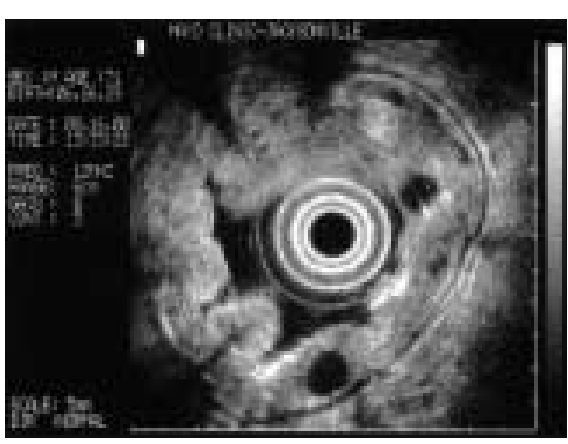

Figure 2 Since there has been at least one report of gastric adenocarcinoma occurring in Cronkhite-Canada syndrome, endosonography was performed to further investigate the gastric wall thickening. This study revealed distinctive submucosal cystic structures. Fine-needle aspiration of the largest cyst was performed; cytology was negative. The significance of these submucosal cysts is not known. 